NBER WORKING PAPER SERIES

\title{
ENDOGENOUS FERTILITY, MORTALITY, AND ECONOMIC GROWTH: CAN A MALTHUSIAN FRAMEWORK ACCOUNT FOR THE CONFLICTING HISTORICAL TRENDS IN POPULATION?
}

\author{
Isaac Ehrlich \\ Jinyoung Kim \\ Working Paper 11590 \\ http://www.nber.org/papers/w11590
}

\section{NATIONAL BUREAU OF ECONOMIC RESEARCH \\ 1050 Massachusetts Avenue \\ Cambridge, MA 02138}

August 2005

The views expressed herein are those of the author(s) and do not necessarily reflect the views of the National Bureau of Economic Research.

(C2005 by Isaac Ehrlich and Jinyoung Kim. All rights reserved. Short sections of text, not to exceed two paragraphs, may be quoted without explicit permission provided that full credit, including $\odot$ notice, is given to the source. 
Endogenous Fertility, Mortality and Economic Growth: Can a Malthusian Framework Account for the Conflicting Historical Trends in Population?

Isaac Ehrlich and Jinyoung Kim

NBER Working Paper No. 11590

August 2005

JEL No. O1, J1, I1

\section{$\underline{\text { ABSTRACT }}$}

The 19th century economist, Thomas Robert Malthus, hypothesized that the long-run supply of labor is completely elastic at a fixed wage-income level because population growth tends to outstrip real output growth. Dynamic equilibrium with constant income and population is achieved through equilibrating adjustments in "positive checks" (mortality, starvation) and "preventive checks" (marriage, fertility). Developing economies since the Industrial Revolution, and more recently especially Asian economies, have experienced steady income growth accompanied by sharply falling fertility and mortality rates. We develop a dynamic model of endogenous fertility, longevity, and human capital formation within a Malthusian framework that allows for diminishing returns to labor but also for the role of human capital as an engine of growth. Our model accounts for economic stagnation with high fertility and mortality and constant population and income, as predicted by Malthus, but also for takeoffs to a growth regime and a demographic transition toward low fertility and mortality rates, and a persistent growth in per-capita income.

Isaac Ehrlich

Department of Economics

University of Buffalo

415 Fronczak Hall

Buffalo, NY 14260-1520

and NBER

mgtehrl@buffalo.edu

Jinyoung Kim

Department of Economics

University of Buffalo

441 Fronczak Hall

Buffalo, NY 14260-1520

jinkim@buffalo.edu 


\section{Introduction}

In his influential book (1798), Thomas Malthus offered a model of economic dynamics, which was designed to explain the stylized facts concerning the dynamic relation between population and income, as he saw it from his historical vantage point. The essential features of his model were a tendency of the economy to seek a dynamic, stagnant equilibrium characterized by high fertility, high mortality, stagnant population, and very low level of per-capita income. He hypothesized that population growth depends on the economy's material conditions, especially food supply, because mankind's biological capacity of reproduction exceeds its physical capacity to produce food. Without restraint, population would increase geometrically, but food production would increase only arithmetically. Since survival requires a minimum level of food consumption, population growth would eventually be checked by the growth in food production and per capita consumption would fall to a dismally low level — an outcome commonly called the 'Malthusian trap'. Rising consumption and income would be completely absorbed by an increase in population induced by positive checks on the death rate through 'misery and vice' (the periodic outbreak of wars, pestilence, starvation and disease) or by preventive checks on the birth rate through 'moral restraint' (the postponement of marriage due to fear of hunger).

Despite its rigid conditions, this was the first systematic attempt to offer a complete model of economic growth and personal income determination, based on micro foundations, since it covers the essential behavioral factors contributing to dynamic equilibrium: fertility, mortality, and the production side of the economy.

The Malthusian paradigm can be restated more formally in terms of both its static and dynamic components. The long-run population supply schedule is assumed to be infinitely 
elastic at an arbitrarily low wage level, w*, commonly identified with 'subsistence', although this is not a necessary outcome of Malthus's paradigm as we derive it in this paper (see also Becker, 1988 and Ehrlich and Lui, 1997). There is an 'iron law' of wages: The static demand schedule, representing labor productivity at food production, can be depicted as an inverted Ushaped curve intersecting the horizontal supply schedule from both below and above. Under static conditions the stable equilibrium population level, $\mathrm{N}^{*}$, is determined at the point where the demand schedule intersects the supply schedule from above. (The point where the former curve intersects the latter from below would be an unstable equilibrium.) Any level of wage, or per capita income higher than $\mathrm{w}^{*}$ would diminish the preventive checks on marriage, hence fertility, while any level below $\mathrm{w}^{*}$ would trigger the positive checks on morbidity and mortality. These preventive and positive checks are not effective in the long run, however. The ultimate restraint on population is that people cannot live either below or above $w^{*}$ for too long. Malthus's dynamic equilibrium can thus be deduced as a steady state in which population growth is determined by the arithmetic rate of increase in food supply, which determines the dynamic locations of the derived-demand curve for labor.

According to Ricardo's interpretation of Malthus' ideas, an essential hypothesis underlying Malthus's work is the scarcity of land and the law of diminishing returns to labor farming fixed land. By assuming that labor and the working capital required for farming always combine in fixed proportions, the Ricardian model deduced that population would continue to expand just as long as the residual profits of capitalists (but not the rent on land going to landlords) remained positive, fueling additional investments. This would be the case as long as the marginal product of labor on fixed land would be above labor's "subsistence" pay. While the Ricardian model recognized the possible role of technological progress and industrialization in 
shifting upwards the demand schedule for labor, such shifts were not presumed to modify the iron law of wages unless workers' expectations concerning the 'subsistence' or 'natural' wage were themselves modified in the process.

Malthus's basic prediction of continuing human misery because of the tendency of population to grow at a higher rate than income in the economy has been contradicted in postindustrial revolution era in Europe, as well as in all countries experiencing fast economic development following periods of relative stagnation, most recently in Japan and Asia's Big- and Little-Tigers. In all such countries high mortality and high fertility reversed course as per-capita real income started taking off from stagnating low levels into a regime of generally persistent growth - a process characterized as a "demographic transition".

Recent literature on endogenous growth with finitely lived agents has attempted to rationalize these demographic developments using a human capital approach to economic development, e.g., Becker, Murphy, and Tamura [BMT] (1990) and Ehrlich and Lui [EL] (1991) (see especially the section titled a "theory of the demographic transition" in EL). These papers are close in spirit to the revised Malthusian model we offer here, which brings into the equation the role of reproducible capital - fundamentally human capital. Yet neither of these papers offered a comprehensive model that accounts for both fertility and mortality or trends in overall population, which is what Malthus's simple, but comprehensive model of economic development sought to explain. In particular, while both BMT's and EL's frameworks explain the evolution of fertility over the transitional development period, and why gross birth rates are higher at a

\footnotetext{
${ }^{1}$ Sato (2002) reports a rapid demographic change that has taken place in Japan since World War II. The total fertility rate reached 1.38 in 1999, well below replacement level, and the share of the population 65 or over has risen from $5 \%$ in 1950 to $17 \%$ in 2000 . He attributes the decline of fertility in Japan to the "preventive check" in the Malthusian theory, i.e. delayed marriage. For documentation on the historical declines in fertility in both East Asia and Europe, see Mason (2002) and Coale and Watkins (1986), respectively.
} 
stagnant equilibrium steady state and fall substantially as the economy takes off toward a growth equilibrium steady state, they do not account for the stagnancy of population under the Malthusian long-term stagnant equilibrium, or the continuous decline of both mortality and fertility over the transitional development period leading to a growth equilibrium steady state. In the Malthusian world, increasing population will lower labor productivity and thus per capita labor income, which in turn will check population growth through its offsetting effects on the death and birth rates. In the BMT and EL models, however, goods are produced by a linear production function of human capital without diminishing returns, mortality is taken to be exogenous, and fertility is not restricted to produce a stagnant population. Consequently, these models predict that fertility will be high and population will be fast growing at the "stagnant equilibrium" stage of development, which is not quite consistent with the historical experience, at least the way it appeared to Malthus. The main purpose of our paper is to extend the analytical framework we ascribe to Malthus by incorporating in the Malthusian framework the role of reproducible capital - fundamentally human capital, thereby accounting for the stylized facts of economic dynamics as seen during his times, as well as for the historical experience of economic development and persistent growth starting in Europe and the West throughout the $19^{\text {th }}$ and early $20^{\text {th }}$ Centuries, and in the fast developing Asian economies post World War II.

The two key aspects of the Malthusian theory that are adopted in our model in order to produce a Malthusian interpretation of both pre- and post-Malthusian trends in the relation between population and economic growth and development are: (i) diminishing marginal product of labor in goods production; and (ii) endogenous mortality, as well as fertility. By introducing these features in an overlapping-generations model with human capital as a possible engine of economic growth, we attempt to account for the possibility that an economy would be stuck in a 
Malthusian trap regime, where fertility and mortality are high, but population size and per-capita income are stagnant, as well as for the possibility that such economies can also experience economic and demographic takeoff and transition into a persistent growth regime of low fertility and mortality and continuous per-capita income growth.

The rest of this paper is organized as follows: The next section summarizes the literature on economic development that attempts to explain simultaneously the existence of a stagnant regime as well a phase of transition to a persistent growth regime. In section III we set up our benchmark model treating non-reproducible physical capital (land) as fixed, fertility and human capital formation as control variables, and mortality risks as a product of community consumption or wealth and derive its behavioral and equilibrium properties. The advantage of this framework is that it preserves the essential features of the Malthusian framework, but allows us to derive closed-form solutions to population and income growth. In section IV we derive this model's dynamic implications and simulate transitional development paths. In section $\mathrm{V}$ we then introduce an extended framework where mortality risks are subject to full individual control as well, which requires solutions by numerical methods. Section V concludes.

\section{Literature Review}

In recent literature on economic growth, various studies attempt to explain both stagnancy of income and population for long periods of time, followed by dramatic changes in income and population growth within one unified framework. Galor and Weil (2000) describe the stylized long-run economic and demographic development over three stages: an initial Malthusian regime when the growth rates of population and per-capita income are both low, a Post-Malthusian regime with higher growth rates of both population and per-capita income, and finally a modern growth regime with a falling population growth rate, but an accelerated growth 
rate of per capita income. This paper relies on the strong assumption that human capital accumulated by one generation is fully inherited by the next generation and it omits mortality as an endogenous variable. It also predicts low fertility in the Malthusian regime, which is not consistent with historical evidence. Other papers that attempt to account for economic and demographic developments without explicit consideration of mortality include Kremer (1993), Hansen and Prescott (2002), Tamura (2002), Lucas (2004), Doepke (2004), and Galor and Moav (2004).

An early paper that allows explicitly for mortality and growth is Ehrlich and Lui (1991). They show that an exogenous fall in mortality raises the rate of return to human capital, induces parents to substitute quantity for quality, and thus pulls the economy to a sustained growth path. However, mortality is either absent or taken to be an exogenous parameter in that paper. Kalemli-Ozcan, Ryder, and Weil (2000) employ similar mechanisms in a continuous time, overlapping-generations framework.

Several recent papers have attempted to extend this literature by modeling mortality as an endogenous variable, which depends, however, not on direct investments in health, but on other variables characterizing the stage of economic development. In Morand (2000), the other variable is human capital level while it is consumption in Jones (2001), per capita income in Kalemli-Ozcan (2002), and population density and human capital in Lagerlof (2003). A common feature of these papers is the assumption that impact of these variables on mortality is external to the agent's optimization problem, and thus has no feedback effect on the agent's choice of fertility or accumulation of human capital. Unlike these models, the agent, or parent, in our model takes into account explicitly the impact of parental choices on mortality. Moreover, our paper differs from these papers in that we model adult mortality (which is determined by 
agents' own consumption decision) as well as child mortality (that is shaped by parents) while others only consider child mortality. At the same time we preserve the Malthusian world of production by recognizing the existence of a non-reproducible, and largely capital asset, such as arable land or the "environment", as well as a reproducible capital asset which we identify as human capital, but which can also represent reproducible physical capita which is proportional to human capital over the process of economic development (as it is in the long-run equilibrium of Lucas, 1987).

\section{The Benchmark Model}

We consider an overlapping generation model of a representative agent, where each agent lives through three periods: childhood, adulthood, and old age. All family-based decisions are made during adulthood by parents. Young children depend on their parents for nurture and investments in human capital. Parents are motivated by pure altruism toward their children.

The Economy: Following the essential feature of the Malthusian model, we assume the existence of a fixed amount of non-reproducible capital in the economy, L. The fixed asset can be interpreted as "land", or more generally, in contemporary terms, the global "environment". The technology driving production is a function of this non-reproducible fixed asset, as well as of an agent's production capacity, including a "raw" physical labor endowment, $\overline{\mathrm{H}}$, and a reproducible asset identified as human capital, $\mathrm{H}_{\mathrm{t}}$. (In practice, the latter can include reproducible physical capital as well, which is, however, not tradable and fully depreciates within a single generation.) Labor supply is assumed to be completely inelastic, for simplicity, consistent with the spirit of the Malthusian paradigm. The production function of an aggregate consumption good exhibits CRTS in all assets (see equation (8) below). With a fixed supply of the nonreproducible capital, L, this implies the existence of diminishing returns of labor capacity or land 
in goods production. Health is an implicit asset in this economy, which affects the probability of survival of children to adulthood $\pi_{1}$ and that of adults to old age, $\pi_{2}$. Health is treated as an endogenous asset in this paper, but in our benchmark model, it is determined largely by the average consumption of the representative agent in the community. In our extended formulations, we allow the probabilities of mortality to be treated as endogenous decision variables at the individual household level as well. The population of parents (workers), N, is controlled by fertility and mortality. The economy is assumed to be competitive in the labor and goods markets.

A young parent maximizes an altruistic expected utility (1) by choosing fertility $\left(\mathrm{n}_{\mathrm{t}}\right)$ and human capital investment per child $\left(\mathrm{h}_{\mathrm{t}}\right)$ :

(1) $\mathrm{U}=[1 /(1-\sigma)]\left[\mathrm{C}_{1, \mathrm{t}}{ }^{1-\sigma}-1\right]+\delta \pi_{2}[1 /(1-\sigma)]\left\{\left[\mathrm{C}_{2, \mathrm{t}+1}{ }^{1-\sigma}-1\right]+\left[\mathrm{C}_{3, \mathrm{t}+1}{ }^{1-\sigma}-1\right]\right\}$, where

(2) $\mathrm{C}_{1, \mathrm{t}}=\left(1-\mathrm{vn}_{\mathrm{t}}-\theta \mathrm{h}_{\mathrm{t}} \mathrm{n}_{\mathrm{t}}\right) \mathrm{w}_{\mathrm{t}}\left(\overline{\mathrm{H}}+\mathrm{H}_{\mathrm{t}}\right)$,

(3) $\mathrm{C}_{2, t+1}=r_{t+1} B_{t}$,

(4) $\mathrm{C}_{3, t+1}=\mathrm{B}\left[\pi_{1} \mathrm{n}_{\mathrm{t}}\right]^{\beta}\left[\mathrm{w}_{\mathrm{t}+1}\left(\overline{\mathrm{H}}+\mathrm{H}_{\mathrm{t}+1}\right)\right]^{\alpha}$,

(5) $H_{t+1}=A\left(\bar{H}+H_{t}\right) h_{t}$

with $\mathrm{w}_{\mathrm{t}}, \mathrm{w}_{\mathrm{t}+1}, \mathrm{r}_{\mathrm{t}+1}$, and $\mathrm{B}_{\mathrm{t}}$, taken as given at the individual level.

In equation (2), $\mathrm{C}_{1, \mathrm{t}}$ and $\mathrm{n}_{\mathrm{t}}$ represent a young parent's consumption and the number of children per parent (treated as a continuous variable), while the parameters $\mathrm{v}$ and $\theta$ represent unit costs of rearing and financing education of a child as a share of full income, $\mathrm{h}_{\mathrm{t}}$ the uniform educational investment in each as a share of full income, and $\mathrm{w}_{\mathrm{t}}$ the wage rate, or rental price, of a unit of human capital. Total labor income is thus the product of $\mathrm{w}_{t}$ and production capacity, $\left(\overline{\mathrm{H}}+\mathrm{H}_{\mathrm{t}}\right)$. The variables $\pi_{1}$ and $\pi_{2}$ denote probabilities of survival from childhood to adulthood and from adulthood to old age, while $\delta$ is a discount factor and $\sigma$ if the inverse of the elasticity of 
substitution in consumption $(0<\sigma<1)$.

Preserving the spirit of a simple Malthusian world, in which the opportunities to affect health through individual spending on effective medical care and other means of life protection on the job, or at home, was quite limited, we first specify a benchmark case in which the probabilities of survival of both young parents and children are functions of the average consumption level of young parents in the community, $\mathrm{C}_{1, \mathrm{t}} \mathrm{m}$, so that a young adult takes the effect of $\mathrm{C}_{1, \mathrm{t}}{ }^{\mathrm{m}}$ on the probabilities as given in the optimization problem:

(6) $\pi_{1}=\pi_{1}\left(\mathrm{C}_{1, \mathrm{t}}{ }^{\mathrm{m}} ; \mathrm{D}\right)$ and $\pi_{2}=\pi_{2}\left(\mathrm{C}_{1, \mathrm{t}}^{\mathrm{m}} ; \mathrm{D}\right)$,

where D is a "medical technology" parameter that affects both survival probabilities.

This simplifying assumption, which we relax in section $\mathrm{V}$ of this paper, attempts to follow Malthus' idea that population is checked by rising death rate through starvation. The rationale of viewing the consumption effect on mortality as an externality in the benchmark model is that "public goods" like the sanitation, sewage, and vaccination, as well as the average consumption of food in the community, have played a crucial role in determining the onslaught of life-threatening disease in the community, and thus also the odds of individual mortality, rather than an individual agent's decision. We assume that these survival probabilities are positively related to $\mathrm{C}_{1, t} \mathrm{~m}$, converging to the upper limits $\bar{\pi}_{1}$ and $\bar{\pi}_{2}$ when $\mathrm{C}_{1, \mathrm{t}}^{\mathrm{m}}$ goes to infinity. (Note that, alternatively, we can also assume that these probabilities are functions of the average community income, rather than consumption of the young parent's generation, which would yield identical theoretical results.) In our representative-agent model, $\mathrm{C}_{1, \mathrm{t}}{ }^{\mathrm{m}}-$ the average consumption of a young parent in the community - becomes equal to the optimal consumption level of any individual parent, $\mathrm{C}_{1, \mathrm{t}}$.

In equation (3), $\mathrm{C}_{2, t+1}$ is the consumption of a parent at old age. For analytical simplicity, 
we assume that an agent inherits a non-reproducible asset (a family share of land, farm, or firm) bequeathed by the parent, which is the only source of income at old age. $B_{t}$ is the amount of the non-reproducible asset inherited, and $\mathrm{r}_{\mathrm{t}+1}$ denotes the asset's equilibrium rate of return, as determined at the market level. $\mathrm{B}_{\mathrm{t}}$ and $\mathrm{r}_{\mathrm{t}+1}$ are taken as given, however, at the individual level, as part of the optimization problem. Since the aggregate amount of the non-reproducible asset is assumed to be constant at the economy-wide level, L, the amount of the inherited asset per adult would be $B_{t}=L /\left(\pi_{2} N_{t}\right)$, where $N_{t}$ is the number of young adults born in period $t-1$.

In equation (4), $\mathrm{C}_{3, t+1}$ defines an "altruism function" in the context of our overlappinggeneration framework, whereby parents derive utility vicariously from the number and income of surviving offspring. This specification is closely related to that of altruism in dynastic models. To ensure interior solutions in both fertility and educational investment in a growth steady state, it is necessary that $\beta>\alpha=1$, otherwise quality would dominate quantity of children in a growthequilibrium steady state: quantity always has a higher marginal cost if investment in education is applied uniformly to all children. To ensure the concavity of the maximization problem, we must further restrict $\beta(1-\sigma)<1$. Hereafter we assume that these conditions hold.

Equation (5) specifies the human capital production technology that links parents' human capital and investment in children's education with the human capital formed in each child at maturity. Like the health stock of a young parent (workers) in the economy, $\mathrm{H}_{\mathrm{t}}$, the population of young parents - another state variable of the model besides - follows the law of motion: (7) $\mathrm{N}_{\mathrm{t}+1}=\pi_{1}\left(\mathrm{C}_{1, \mathrm{t}}^{\mathrm{m}}\right) \mathrm{n}_{\mathrm{t}} \mathrm{N}_{\mathrm{t}}$

The wage rate $\mathrm{w}_{t}$ and the rate of return to the non-reproducible asset $\mathrm{r}_{\mathrm{t}}$ are determined at the marginal productivity in competitive product and input markets where goods are produced by the CRS production function: 
(8) $Y_{t}=\left[\left(\bar{H}+H_{t}\right) N_{t}\right]^{\gamma} L^{1-\gamma}=w_{t}\left(\bar{H}+H_{t}\right) N_{t}+r_{t} L$,

where $\mathrm{w}_{\mathrm{t}}=\gamma\left[\left(\overline{\mathrm{H}}+\mathrm{H}_{\mathrm{t}}\right) \mathrm{N}_{\mathrm{t}}\right]^{\gamma-1} \mathrm{~L}^{1-\gamma}$ and $\mathrm{r}_{\mathrm{t}}=(1-\gamma)\left[\left(\overline{\mathrm{H}}+\mathrm{H}_{\mathrm{t}}\right) \mathrm{N}_{\mathrm{t}}\right]^{\gamma} \mathrm{L}^{-\gamma}$. The price of goods is normalized as 1 . Note that this goods production function has the property of diminishing returns to both labor in human capital efficiency unit and the non-reproducible asset. Since firms earn zero profit, the number of firms is indeterminate in this model. Note that since we do not allow for saving or borrowing in this economy, optimal consumption at adulthood and old age are set by the budget constraints in equations (2) and (3). Maximizing equation (1) with respect to fertility, $\mathrm{n}_{\mathrm{t}}$, and investment in human capital, $\mathrm{h}_{\mathrm{t}}$, yields the following pair of first-order conditions:

(9) $0 \geq \mathrm{C}_{1, \mathrm{t}}{ }^{-\sigma}\left(-\mathrm{v}-\theta \mathrm{h}_{\mathrm{t}}\right) \mathrm{w}_{\mathrm{t}}\left(\overline{\mathrm{H}}+\mathrm{H}_{\mathrm{t}}\right)+\delta \pi_{2}\left(\mathrm{C}_{1, \mathrm{t}}{ }^{\mathrm{m}}\right) \mathrm{C}_{3, \mathrm{t}+1}{ }^{-\sigma} \beta \mathrm{B} \pi_{1}\left(\mathrm{C}_{1, \mathrm{t}}\right)^{\beta} \mathrm{n}_{\mathrm{t}}^{\beta-1} \mathrm{w}_{\mathrm{t}+1}\left(\overline{\mathrm{H}}+\mathrm{H}_{\mathrm{t}+1}\right)$,

(10) $0 \geq \mathrm{C}_{1, \mathrm{t}}{ }^{-\sigma}\left(-\theta \mathrm{n}_{\mathrm{t}}\right) \mathrm{w}_{\mathrm{t}}\left(\overline{\mathrm{H}}+\mathrm{H}_{\mathrm{t}}\right)+\delta \pi_{2}\left(\mathrm{C}_{1, \mathrm{t}}^{\mathrm{m}}\right) \mathrm{C}_{3, \mathrm{t}+1}{ }^{-\sigma} \mathrm{B} \pi_{1}\left(\mathrm{C}_{1, \mathrm{t}}{ }^{\mathrm{m}}\right)^{\beta} \mathrm{n}_{\mathrm{t}}^{\beta} \mathrm{w}_{\mathrm{t}+1} \mathrm{~A}\left(\overline{\mathrm{H}}+\mathrm{H}_{\mathrm{t}}\right)$.

An interesting feature of these optimality conditions concerning the control variables $n_{t}$ and $h_{t}$ is their dependence on two underlying parameters: the human capital productivity parameter $\mathrm{A}$ in equation (5), and the financial unit cost of investment in human capital, $\theta$. Equations (9) and (10) indicate that the equilibrium solutions for fertility and the fraction of full income spent on educating each child, $\theta \mathrm{h}_{\mathrm{t}}$, depend strictly on "investment efficiency", or the ratio of productivity to the unit financing-cost of investment, $\mathrm{e} \equiv \mathrm{A} / \theta$, as can be shown by rewriting equations (9) and (10) as the optimality conditions for $\mathrm{n}_{\mathrm{t}}$ and $\theta \mathrm{h}_{\mathrm{t}}$.

If the model has interior solutions for $\mathrm{n}_{\mathrm{t}}$, and $\mathrm{h}_{\mathrm{t}}$, so equations (9) and (10) are written as equalities, then, by combining these equations, $h_{t}$ can be solved for explicitly as:

(11) $\mathrm{h}_{\mathrm{t}}=\left\{\mathrm{v}-\beta \overline{\mathrm{H}} /\left[\mathrm{A}\left(\overline{\mathrm{H}}+\mathrm{H}_{\mathrm{t}}\right) / \theta\right]\right\} /[\theta(\beta-1)]$.

Inserting equation (11) into equation (5) we obtain an explicit equilibrium law of motion for human capital formation at the individual agent's level as a linear equation:

(12) $\mathrm{H}_{\mathrm{t}+1}=(\mathrm{Av} / \theta-\beta) \overline{\mathrm{H}} /(\beta-1)+\{\mathrm{Av} /[\theta(\beta-1)]\} \mathrm{H}_{\mathrm{t}}$. 
with a positive slope, $\operatorname{Av} /[\theta(\beta-1)]($ as $\beta>1)$, and a constant term $(\operatorname{Av} / \theta-\beta) \overline{\mathrm{H}} /(\beta-1)$, which could be either positive or negative, depending upon whether Av/ $\theta$ exceeds or falls short of $\beta$.

Total population size is defined as

(13) $\mathrm{P}_{\mathrm{t}+1}=\mathrm{n}_{\mathrm{t}+1} \pi_{1}\left(\mathrm{C}_{1, \mathrm{t}}^{\mathrm{m}}\right) \mathrm{n}_{\mathrm{t}} \mathrm{N}_{\mathrm{t}}+\pi_{1}\left(\mathrm{C}_{1, \mathrm{t}}^{\mathrm{m}}\right) \mathrm{n}_{\mathrm{t}} \mathrm{N}_{\mathrm{t}}+\pi_{2}\left(\mathrm{C}_{1, \mathrm{t}}^{\mathrm{m}}\right) \mathrm{N}_{\mathrm{t}}$,

where the first, second and third term represents the number of children, young adults, and old adults in period $\mathrm{t}+1$, respectively.

In deriving the dynamic solutions for this economy, we impose the equilibrium condition that the average consumption of a representative young parent in the community be equal to the optimal consumption level of an individual parent, or $\mathrm{C}_{1, \mathrm{t}}^{\mathrm{m}}=\mathrm{C}_{1, \mathrm{t}}$.

\section{Dynamic Implications}

By imposing the equilibrium conditions in the economy, whereby all optimal choices at the individual level, and thus the equation of motion for human capital formation, are equal to their average values in the economy, we can show that two stable steady states exist for the economy, corresponding to different parameter values dictating the production and utility functions: a stagnant equilibrium (s), and perpetual growth equilibrium, (g) steady state. The transitional development phase connecting the two is supported by the same parameter set that sustains the perpetual growth regime.

\section{A. Stagnant Equilibrium Steady State}

We can show that there exists a stable stagnant-equilibrium steady state in this model where all control and state variables, including population size, are constant over time. The following proposition describes a stable stagnant steady state.

Proposition 1. Suppose that the constant term in equation (12) is negative algebraically, or Av/ $<<$ $\beta$. It can then be shown that a stable stagnant steady state exists where $h(s)=H(s)=0$ and the 
equilibrium fertility rate $\mathrm{n}(\mathrm{s})$, adult population size $\mathrm{N}(\mathrm{s})$, and total population size $\mathrm{P}(\mathrm{s})$ are constant over time. Specifically, the steady state values of $\mathrm{n}(\mathrm{s})$ and $\mathrm{N}(\mathrm{s})$ satisfy the following two equations:

(14) $\mathrm{v}=\beta \delta \pi_{2}\left(\mathrm{C}_{1}(\mathrm{~s})\right) \mathrm{B}^{1-\sigma} \pi_{1}\left(\mathrm{C}_{1}(\mathrm{~s})\right)^{(\beta+\gamma-1)(1-\sigma)} \mathrm{n}(\mathrm{s})^{(\beta+\gamma-1)(1-\sigma)-1}[1-\mathrm{vn}(\mathrm{s})]^{\sigma}$,

(15) $\pi_{1}\left(C_{1}(s)\right) n(s)=1$

where $C_{1}(s)=[1-v n(s)] w(s) \bar{H}$, and $w(s)=\gamma \bar{H}^{\gamma} N(s)^{\gamma-1} L^{1-\gamma}$.

Proof. Equilibrium human capital formation, $\mathrm{H}_{\mathrm{t}}$, is evolving over time according to a linear equation of motion as described in equation (12). If the constant term in that equation, $(\mathrm{Av} / \theta-\beta) \overline{\mathrm{H}} /(\beta-1)$, is negative, and the slope of that equation, $\mathrm{dH}_{\mathrm{t}+1} / \mathrm{dH}_{\mathrm{t}}=[\mathrm{Av} / \theta(\beta-1)]$, is less than or equal to 1 , the line relating $\mathrm{H}_{t+1}$ to $\mathrm{H}_{t}$ dynamically, SE in Figure 1, will forever stay below the 45-degree line representing a stagnant level of human capital. We will then have a unique stagnant steady state at $\mathrm{H}_{t}=0$. If the slope of equation (12) is greater than 1 , the line for $\mathrm{H}_{\mathrm{t}+1}$ cuts the 45-degree line from below and thus we have two possible steady states: one at $\mathrm{H}_{\mathrm{t}}=$ 0 that is locally stable, and the other at $\mathrm{H}_{t}>0$ that is unstable. Therefore, a sufficient condition for a stable steady state at $H_{t}=0$ is that the constant term is negative, or $A v / \theta<\beta$.

In the stagnant steady state where $\mathrm{H}_{t}=\mathrm{h}_{\mathrm{t}}=0$, the first-order condition for $\mathrm{n}$ (eq. 9) becomes equation (14) which implies that $\partial \mathrm{n}_{\mathrm{t}} / \partial \mathrm{N}_{\mathrm{t}}<0$. From equation (7):

$$
\begin{aligned}
\mathrm{dN}_{\mathrm{t}+1} / \mathrm{dN}_{\mathrm{t}} & =\pi_{1}{ }^{\prime}\left(\mathrm{C}_{1, \mathrm{t}}^{\mathrm{m}}\right)\left(\partial \mathrm{C}_{1, \mathrm{t}}^{\mathrm{m}} / \partial \mathrm{N}_{\mathrm{t}}\right) \mathrm{n}_{\mathrm{t}} \mathrm{N}_{\mathrm{t}}+\pi_{1}\left(\mathrm{C}_{1, \mathrm{t}}^{\mathrm{m}}\right)\left(\partial \mathrm{n}_{\mathrm{t}} / \partial \mathrm{N}_{\mathrm{t}}\right) \mathrm{N}_{\mathrm{t}}+\pi_{1}\left(\mathrm{C}_{1, \mathrm{t}}^{\mathrm{m}}\right) \mathrm{n}_{\mathrm{t}} \\
& <\mathrm{N}_{\mathrm{t}+1} / \mathrm{N}_{\mathrm{t}}=\pi_{1}\left(\mathrm{C}_{1, \mathrm{t}}^{\mathrm{m}}\right) \mathrm{n}_{\mathrm{t}}
\end{aligned}
$$

where the inequality comes from the fact that $\pi_{1}{ }^{\prime}\left(\mathrm{C}_{1, \mathrm{t}}{ }^{\mathrm{m}}\right)>0,\left(\partial \mathrm{C}_{1, \mathrm{t}}{ }^{\mathrm{m}} / \partial \mathrm{N}_{\mathrm{t}}\right)<0$ and $\left(\partial \mathrm{n}_{\mathrm{t}} / \partial \mathrm{N}_{\mathrm{t}}\right)<0$. This implies that the line for $\mathrm{N}_{\mathrm{t}+1}$ as a function of $\mathrm{N}_{\mathrm{t}}$ cuts the 45-degree line from above. Therefore, there is a stable constant value of adult parents, or workers, N(s), in this steady state equilibrium. The total population size, in turn, is given by

$\left(13^{\prime}\right) \mathrm{P}(\mathrm{s})=\mathrm{n}(\mathrm{s}) \pi_{1}\left(\mathrm{C}_{1}(\mathrm{~s})\right) \mathrm{n}(\mathrm{s}) \mathrm{N}(\mathrm{s})+\pi_{1}\left(\mathrm{C}_{1}(\mathrm{~s})\right) \mathrm{n}(\mathrm{s}) \mathrm{N}(\mathrm{s})+\pi_{2}\left(\mathrm{C}_{1}(\mathrm{~s})\right) \mathrm{N}(\mathrm{s})$ 


$$
=\left[1 / \pi_{1}\left(\mathrm{C}_{1}(\mathrm{~s})\right)+1+\pi_{2}\left(\mathrm{C}_{1}(\mathrm{~s})\right)\right] \mathrm{N}(\mathrm{s}),
$$

which is also constant in a the stagnant steady state. (The second term comes from equation 15).

This proposition indicates that parents do not invest in children's human capital if the productivity parameter affecting human capital investment (A) is low, altruism toward the quantity of children $(\beta)$ is strong relative to that toward the quality, or the cost for the quantity of children (v) is so low relative to the unit cost of human capital $(\theta)$ that parents opt to give absolute priority to quantity over quality of children. The intuition behind the result that a long-run stagnant equilibrium of a Malthusian nature involves a constant population, despite the existence of a high fertility rate, is straightforward: Suppose population is growing due to high fertility. This will lower the wage rate (due to the diminishing marginal product of labor) and thus consumption. As consumption falls, the survival probability of children to adulthood $\pi_{1}\left(\mathrm{C}_{1, t}{ }^{\mathrm{m}}\right)$ falls as well, which lowers the marginal utility of having children and thus fertility. This process continues until fertility gets to be low enough that population growth halts, or $\mathrm{N}_{\mathrm{t}+1}$ in equation (7) becomes identically equal to $\mathrm{N}_{\mathrm{t}}$.

Note that a stagnant steady state in our model implies stagnancy of our control and state variables, including per-capita income or consumption, and population, but not necessarily constancy of the levels of these variables: an upward parametric shock in, say, the technology of learning, or human capital (information) production may raise the stagnant level of human capital formation, hence population size and consumption, but may not be sufficiently large to induce a takeoff into a regime of persistent growth, which we consider next.

\section{B. Growth Equilibrium Steady State}

Depending on the underlying values of the model's basic parameters, we can also have a stable growth-equilibrium steady state, which is obtained subject to the following conditions: 
Proposition 2. Suppose that the constant term in equation (12) is non-negative algebraically, or $\operatorname{Av} / \theta \geq \beta$. In this case there exists a stable growth-equilibrium in the economy whereby the state variables $H_{t}$ and possibly $N_{t}$ grow without bound while the long-run values of $n(g)$ and $h(g)$ converge to constant levels. The equilibrium value of human capital investment in the growth steady state is given by:

(16) $\mathrm{h}(\mathrm{g})=\mathrm{v} /[\theta(\beta-1)]$,

and the equilibrium value of fertility in the growth steady state can be derived implicitly from: (17) $(\mathrm{v}+\theta \mathrm{h}(\mathrm{g}))=\beta \delta \bar{\pi}_{2} \mathrm{~B}^{1-\sigma} \bar{\pi}_{1}^{(\beta+\gamma-1)(1-\sigma)} \mathrm{n}(\mathrm{g})^{(\beta+\gamma-1)(1-\sigma)-1}[1-\mathrm{vn}(\mathrm{g})-\theta \mathrm{h}(\mathrm{g}) \mathrm{n}(\mathrm{g})]^{\sigma}[\mathrm{Ah}(\mathrm{g})]^{\gamma(1-\sigma)}$. In the special case of logarithmic utility, the explicit solution for $\mathrm{n}(\mathrm{g})$ is given by (18) $\mathrm{n}(\mathrm{g})=(\beta-1) \delta \bar{\pi}_{2} /\left[\mathrm{v}\left(1+\beta \delta \bar{\pi}_{2}\right)\right]$.

Proof. From equation (12), $\mathrm{H}_{\mathrm{t}}$ grows without bound if the constant term of the equation of motion is equal to or greater than 0 , i.e. $A v / \theta \geq \beta$, since the slope $d_{t+1} / d H_{t}=[A v / \theta(\beta-1)]$ will then be strictly larger than 1 ( $\beta>1$ is a necessary condition to assure that optimal fertility, $n$, is positive). As $H_{t}$ continues to grow without bound, h converges to its constant value $v /[\theta(\beta-1)]$ in equation (11), and the steady state equilibrium growth rate of per-capita income will be positive, Ah- $1 \equiv \mathrm{g}>0$. The first-order optimality condition with respect to $\mathrm{n}$ (eq. 9) is then given by equation (17), since the survival probabilities $\pi_{1}$ and $\pi_{2}$ converge to the upper limits $\bar{\pi}_{1}$ and $\bar{\pi}_{2}$ in the growth steady state as consumption increases without bound.

From equation (13), in this growth equilibrium, the total population size $\mathrm{P}_{\mathrm{t}+1}$, unlike the equilibrium population size under a stagnant equilibrium, is no longer constant; it grows at the same rate as the adult population size $\mathrm{N}_{\mathrm{t}+1}$, since fertility is constant and all survival probabilities converge to their upper limits. 


\section{Transitional Phase}

Discrete upward jumps in one or all of the parameters $A, v$, and $1 / \theta$ can trigger a take-off from a stagnant steady state equilibrium into a regime of self-sustaining growth characterized by a period of demographic transition in which the portion of full income spent on investment in human capital, $h$, rises from 0 and ultimately converges on $v /[\theta(\beta-1)]$, while the rate of fertility falls as the economy moves from a stagnant to a growth equilibrium. What explains this breaking out of the Malthusian trap is the incentive of parents to invest more of their resources in educating children, rather than bearing more of them, as the productivity and resulting welfare benefits of human capital investments, or the cost of specializing in bearing children increase sufficiently from their stagnant equilibrium levels.

Figure 2 shows some illustrations of time paths of the control and state variables in our model when the transition is initiated with a sufficiently large jump in the technology of human capital investment, A. We use the following set of initial parameter values: $\sigma=0.7, \delta=0.8, \bar{\pi}_{1}=$ $0.95, \bar{\pi}_{2}=0.7, \mathrm{v}=0.01, \mathrm{~L}=1, \mathrm{~B}=0.1, \beta=1.03, \gamma=0.75, \theta=1, \overline{\mathrm{H}}=1$, and $\mathrm{A}=1$. Parameter $\mathrm{A}$ is then raised from 1 to 110 and generates a takeoff to a growth regime. The survival probabilities are technically specified by the following functions:

$\pi_{1}\left(\mathrm{C}_{1, \mathrm{t}}^{\mathrm{m}}\right)=\mathrm{D} \bar{\pi}_{1} /\left[1+\left(\mathrm{C}_{1, \mathrm{t}}^{\mathrm{m}}\right)^{-\mu} \exp \left(-\mathrm{C}_{1, \mathrm{t}}^{\mathrm{m}}\right)\right]$, and

$\pi_{2}\left(\mathrm{C}_{1, \mathrm{t}}^{\mathrm{m}}\right)=\mathrm{D} \bar{\pi}_{2} /\left[1+\left(\mathrm{C}_{1, \mathrm{t}}^{\mathrm{m}}\right)^{-\mu} \exp \left(-\mathrm{C}_{1, \mathrm{t}} \mathrm{m}\right)\right]$

where $\mu=0.5$ and $D=1$. These functions satisfy the required conditions that (a) $\pi_{i}(0)=0$, (b) $\pi_{\mathrm{i}}^{\prime}(0)=\infty,(\mathrm{c}) \pi_{\mathrm{i}}\left(\mathrm{C}_{1, \mathrm{t}}^{\mathrm{m}}\right) \rightarrow \bar{\pi}_{\mathrm{i}}$ as $\mathrm{C}_{1, \mathrm{t}}^{\mathrm{m}} \rightarrow \infty$, and (d) $\pi_{\mathrm{i}}^{\prime}\left(\mathrm{C}_{1, \mathrm{t}}^{\mathrm{m}}\right) \rightarrow 0$ as $\mathrm{C}_{1, \mathrm{t}}^{\mathrm{m}} \rightarrow \infty$, for $\mathrm{i}=1,2$.

In Figure 2a, human capital investment h gradually rises from 0 to the growth steady state value. Fertility n, on the other hand, falls from a stagnant steady state value to a growth steady 
state value (Figure $2 b$ ). An intriguing feature of Figure $2 b$ is that fertility dips over a number of generations following the takeoff period, and then gradually rises to its steady state value. The reason is that in this case, the parameter determining human capital investment productivity, A, rises sufficiently sharply to effect a sharp tradeoff way from quantity toward quality of children, so much so that fertility first falls to a level that is below its long-run, steady-state growth equilibrium value. Note that our model does not specify a priori what is the exact level of the long-term equilibrium population-growth rate - this is determined by the parameters of the model, since the equilibrium level of fertility, $\mathrm{n}$, which is treated as a continuous variable, could be above or below the population-replacement level $\left(1 / \pi_{1}\right)$. The long run population trend could thus be consistent with constant, positive, or negative population growth. It is interesting to note that such a pattern is in fact consistent with recent evidence concerning sharp declines in total fertility rates in some fast developing and developed countries such as Japan (see Sato, 2002), Hong Kong, Korea, Singapore, and Taiwan (see Mason, 2002), which have fallen much below 2.1 children per woman - the level needed to ensure long-term replacement of the population.

However, the path of fertility depicted in Figure $2 b$ is not general. If the technological shock (the rise in A) triggering the takeoff into a persistent growth regime is mild enough, our simulations can also produce a dynamic fertility path that is monotonically decreasing over the transition phase leading to a steady state growth equilibrium. This seems to be more consistent with the dynamic pattern of fertility change in the US during the last century. ${ }^{2}$ Following the take-off phase, consumption grows without bound as human capital $\mathrm{H}$ continues to accumulate.

\footnotetext{
${ }^{2}$ A sharp rise in technology that enhances human capital formation (A) is more likely to have occurred in recent decades than in the last century, since in today's global economy, countries starting from a low-level stagnant equilibrium can experience a takeoff partly through technology transfers from developed countries who have attained comparatively much higher technological levels.
} 
The survival probabilities thus eventually converge to their upper limits as the economy approaches the growth steady state (see Fig 2c).

What about trends in population size? Figure $2 \mathrm{~d}$ shows its dynamic path over time. Although the survival probabilities rise, population falls due to the falling fertility levels over the relatively early phase of the transition. However, as the economy approaches a growth equilibrium, population ultimately increases at a steady-state constant rate, equal to the fertility rate per parent, $\mathrm{n}(\mathrm{g})$.

Another experiment we conduct is by allowing for an exogenous shock at a stagnant steady state, such as an advance in the "medical technology" parameter, D, that uplifts simultaneously the survival probabilities $\pi_{1}$ and $\pi_{2}$ and is then followed by an increase in the human capital productivity parameter A in the next generation. Figure 3 shows the simulation results when the value of the "medical technology" parameter, $\mathrm{D}$, initially set at $2 / 3$ in the stagnant equilibrium, is raised, and is then followed by an increase in A from 1 to 110 . We use this exercise to simulate the historical observation in many developed economies that the fall in the average mortality rate occurs prior the takeoff, or transitional development phase. While the time path of human capital investment $\mathrm{h}$ takes a similar pattern as in Figure 2, the time path of fertility $n$ shows an initial surge when the economy experiences an upward shock in the survivor probabilities, to be followed by a phase of continuous decline toward its growth-equilibrium, steady state value. Population, in turn, initially increases because of the initial fertility surge and then falls as fertility decreases. Once the development phase draws closer to a growthequilibrium steady state, population growth settles on a constant, steady growth rate. 


\section{An Extended Model}

We now extend the model to consider the case where survival probabilities depend on an individual agent's own decisions. Specifically, we assume that the adult parent's own consumption in adulthood improves one's survival probability at old age, $\pi_{2}$, as well as the survival probability of one's children, $\pi_{1}$; i.e., children's survival probabilities are specified as functions of individual parents' consumption, $\pi_{1}=\pi_{1}\left(\mathrm{C}_{1, \mathrm{t}}\right)$, and $\pi_{2}=\pi_{2}\left(\mathrm{C}_{1, \mathrm{t}}\right)$. In this framework, when the young parent selects optimal values of fertility and investment in children's human capital, this is done with an explicit consideration of the feedback effects flowing from the parent's own consumption on the survival probabilities $\pi_{1}$ and $\pi_{2}$, and thus on the parent's utility. In the benchmark model, in contrast, survival probabilities were assumed to be strictly a function of the average consumption level in the community (the economy), so the parent's own consumption decision could not affect it directly.

The first order optimization conditions in the extended model are

$$
\begin{aligned}
& \text { (9') } 0 \geq \mathrm{C}_{1, \mathrm{t}}{ }^{-\sigma}\left(-\mathrm{v}-\mathrm{h}_{\mathrm{t}}\right) \mathrm{w}_{\mathrm{t}}\left(\overline{\mathrm{H}}+\mathrm{H}_{\mathrm{t}}\right)+\delta \pi_{2} \mathrm{C}_{3, \mathrm{t}+1}{ }^{-\sigma} \beta \mathrm{B} \pi_{1}{ }^{\beta} \mathrm{n}_{\mathrm{t}}^{\beta-1} \mathrm{w}_{\mathrm{t}+1}\left(\overline{\mathrm{H}}+\mathrm{H}_{\mathrm{t}+1}\right) \\
& +\left\{\delta \pi_{2}{ }^{\prime}[1 /(1-\sigma)]\left[\mathrm{C}_{2, \mathrm{t}+1}{ }^{1-\sigma}+\mathrm{C}_{3, \mathrm{t}+1}{ }^{1-\sigma}\right]+\delta \pi_{2} \mathrm{C}_{3, \mathrm{t}+1}{ }^{-\sigma} \beta \mathrm{B} \pi_{1}{ }^{\beta-1} \pi_{1}{ }^{\prime} \mathrm{n}_{\mathrm{t}}{ }^{\beta} \mathrm{w}_{\mathrm{t}+1}\left(\overline{\mathrm{H}}+\mathrm{H}_{\mathrm{t}+1}\right)\right\}\left(-\mathrm{v}-\mathrm{h}_{\mathrm{t}}\right) \mathrm{w}_{\mathrm{t}}\left(\overline{\mathrm{H}}+\mathrm{H}_{\mathrm{t}}\right), \\
& \left(10^{\prime}\right) 0 \geq \mathrm{C}_{1, \mathrm{t}}{ }^{-\sigma}\left(-\mathrm{n}_{\mathrm{t}}\right) \mathrm{w}_{\mathrm{t}}\left(\overline{\mathrm{H}}+\mathrm{H}_{\mathrm{t}}\right)+\delta \pi_{2}\left(\mathrm{C}_{1, \mathrm{t}}{ }^{\mathrm{m}}\right) \mathrm{C}_{3, \mathrm{t}+1}{ }^{-\sigma} \mathrm{B} \pi_{1}\left(\mathrm{C}_{1, \mathrm{t}}{ }^{\mathrm{m}}\right)^{\beta} \mathrm{n}_{\mathrm{t}}^{\beta} \mathrm{w}_{\mathrm{t}+1} \mathrm{~A}\left(\overline{\mathrm{H}}+\mathrm{H}_{\mathrm{t}}\right) \\
& +\left\{\delta \pi_{2}{ }^{\prime}[1 /(1-\sigma)]\left[\mathrm{C}_{2, \mathrm{t}+1}{ }^{1-\sigma}+\mathrm{C}_{3, \mathrm{t}+1}{ }^{1-\sigma}\right]+\delta \pi_{2} \mathrm{C}_{3, \mathrm{t}+1}{ }^{-\sigma} \beta \mathrm{B} \pi_{1}{ }^{\beta-1} \pi_{1}{ }^{\prime} \mathrm{n}_{\mathrm{t}}{ }^{\beta} \mathrm{W}_{\mathrm{t}+1}\left(\overline{\mathrm{H}}+\mathrm{H}_{\mathrm{t}+1}\right)\right\}\left(-\mathrm{n}_{\mathrm{t}}\right) \mathrm{w}_{\mathrm{t}}\left(\overline{\mathrm{H}}+\mathrm{H}_{\mathrm{t}}\right) .
\end{aligned}
$$

The last term in $\left(9^{\prime}\right)$ reflects the additional marginal cost of fertility to the adult parent, since an increase in fertility reduces consumption to the adult parent, which, in turn, lowers the survival probabilities, $\pi_{1}$ and $\pi_{2}$. Similarly, the last term in $\left(10^{\prime}\right)$ describes the additional marginal cost of human capital investment to the adult parent, since an increase in human capital investment reduces consumption in adulthood and thus the optimal survival probabilities. 
Given the existence of interior solutions for $n_{t}$ and $h_{t}$ in this extended model, we can show from equations $\left(9^{\prime}\right)$ and $\left(10^{\prime}\right)$ that the equilibrium value of $h_{t}$ in this extended model is the same as that in equation (11) of the benchmark model: $\mathrm{h}_{\mathrm{t}}=\left\{\mathrm{v}-\beta \overline{\mathrm{H}} /\left[\mathrm{A}\left(\overline{\mathrm{H}}+\mathrm{H}_{\mathrm{t}}\right) / \theta\right]\right\} /[\theta(\beta-1)]$. Since the adult parent's consumption now yields additional benefits to the parent, by raising the survival probabilities, and thus the expected utility, the parent has an incentive to raise optimal consumption, relative to the situation in the benchmark model. This generates an incentive to reduce the optimal investment in human capital. On the other hand, at a given rate of investment, a rise in the survival probabilities raises the parents' expected rate of return on investment in children's human capital, which generates an incentive to increase the optimal investment in children's human capital. Given the functional specification of the altruism function in our model, these opposing effects on the incentive to invest in human capital balance out, so that the net effect on $h_{t}$ is zero. The same result holds in both the persistent growth equilibrium and in the stagnant equilibrium steady states.

Moreover, in the growth equilibrium steady state, the solutions for both fertility and investment in human capital, $\mathrm{n}(\mathrm{g})$ and $\mathrm{h}(\mathrm{g})$ in the extended model are also the same as under the benchmark model. The underlying reason is that since in a persistent growth equilibrium, where consumption continues to grow without bound, the probabilities of survival converge to their maximal values, $\bar{\pi}_{1}$ and $\bar{\pi}_{2}$. On the margin, there is no longer any added feedback effect coming from own consumption decisions on survival probabilities in the extended model, relative to the benchmark model, where survival probabilities were strictly a function of average consumption in the community, which the individual agent must take as given in choosing fertility, human capital investment, and consumption. The steady state growth equilibrium values of all control variables will thus become identical in our extended model relative to the benchmark model. 
The solution for optimal fertility, however, is different under the benchmark and the extended model in a stagnant steady state. The reason is that in the extended model, the feedback effects flowing from optimal consumption by adult parents on their own and their children's survival probabilities provide an added incentive to spend on own consumption relative to investing in children. But since optimal human capital investment per child is the same under the benchmark and the extended specifications, a lower amount of income can then be spent on the quantity of children, in the stagnant equilibrium under the extended model, relative to the benchmark model.

Since no closed-form solution for $\mathrm{n}_{\mathrm{t}}$ exists in the extended model, the equilibrium values of $n_{t}$ must be derived through simulations. The simulated transition paths of the control variables $\mathrm{h}, \mathrm{n}, \pi_{1}, \pi_{2}$ and total population in the extended model bear out the qualitative and quantitative implications of propositions 1 and 2. In all parts of Figure 4 we show the transition paths under the extended model alongside those under the benchmark model following an upward shock in the technology of human capital investment, A, triggering a takeoff from stagnant to growth equilibrium. Figure $4 \mathrm{~b}$ and $4 \mathrm{c}$ show lower fertility, but higher probabilities of survival in the extended model than in the benchmark model in a stagnant steady state and during the transition. Figure 4a, however, shows that the transition path of $\mathrm{h}$ is identical in the extended and benchmark models, and figures $4 \mathrm{~b}$ and $4 \mathrm{c}$ show that the steady state, growth equilibrium values of both fertility, $\mathrm{n}$, and the survival probabilities $\pi_{1}$ and $\pi_{2}$ in the extended model ultimately converge on the same levels as in the benchmark model, in conformity with proposition 2 . The population level, however, is always lower in the extended model relative to the benchmark model: the fertility level is lower when parents take into account the feedback effects of own consumption on survival probabilities, which lowers population levels as well under a stagnant equilibrium steady state. As the economy approaches a growth equilibrium steady state, however, fertility, and thus the growth rate of 
population become the same in both models. The transition path of total population is thus lower in level over the entire development process when parents take into account the effects of own consumption on survival probabilities, as opposed to the case when the latter are controlled strictly by the average level of consumption or wealth in the economy.

\section{Conclusion}

Our objective in this paper has been to see whether one can use a Malthusian framework to explain the conflicting historical evidence on the relationship between population and economic growth since Malthus' days. By a Malthusian framework we mean, in particular, the following basic constraints and opportunities within which economies function: a. maintaining the Malthusian assumption of diminishing marginal productivity of labor because of the limited supply of some non-reproducible resource; b. allowing for the existence of a reproducible resource which is subject to individual and community control; c. explaining both fertility and mortality - the twin determinants of population - as being controlled on the margin by individuals and families, largely through (food) consumption. Our paper shows that the answer to this basic question is affirmative.

In conformity with the Malthusian analytical framework, we distinguish reproducible capital, identified essentially as human capital, from some non-reproducible capital - land, or the "environment", or some other public good - that is available at limited supply to the economy, although we do not consider non-reproducible capital to pose a crucial constraint on growth because of the dynamic role of human capital as an engine of growth. Like Malthus we allow the family - specifically adult parents - to determine own consumption at adulthood and old age, the quantity and quality of (human capital investment in) children, and the probability of survival of themselves, into old age, and of their children, into adulthood. This is a comprehensive agenda, 
which is nevertheless facilitated by using a simple Malthusian framework. We allow for two versions of individual control over longevity through consumption: a. by virtue of the average level of consumption (or wealth) in the community (the economy), which can affect longevity essentially by promoting public health - sewage, hygiene in public places, and public vaccination; $b$. through individual recognition of the consequences of own consumption on own and children's health.

Despite the simplicity of the model (e.g., abstracting from capital markets, the role of firms in production, and institutional changes), we are able to use these versions of a Malthusian framework to explain why Malthus was both right and wrong in predicting the association between population and growth. He was right in his own days, when the levels of basic parameters controlling the economy dictated economies experiencing a Malthusian trap. What Malthus did not take into account is the potentially powerful effect of discrete technological shocks through inventions and basic research that would free the economy from the "trap", and jump-start it into a regime of perpetual growth.

Using the basic Malthusian analytical framework, we are able to project some basic features of the demographic transition that took place in many countries over the 200 years or so following his work. Unlike previous models of endogenous growth, both versions of our refined Malthusian model produce a constant population under a low-level stagnant equilibrium steady state, but show that this does not mean a constant population level, since mild technological shocks can affect the levels of both population and per-capita income without generating a takeoff to a persistent growth regime. In both versions of our model, fertility - high under a stagnant equilibrium - shows a general sharp decline following takeoff, either immediately after takeoff, or after an initial phase in which it first rises and then falls. Whether fertility first rises 
before its decline is shown to be the result of the technical shock triggering the takeoff: if the initial trigger is an exogenous discovery of some life-saving technology, population first rises before it enters its declining phase. Moreover, a few generations following takeoff, fertility tends to drop below its equilibrium, steady-state value under growth equilibrium, before inching up back to that level. Mortality risks, in contrast, are low under a stagnant equilibrium steady state, are also generally continuously rising following the discrete technological improvement in learning productivity, or information production, which triggers the economic takeoff.

Most intriguing, our reformulation of the simple Malthusian model, can trace with some degree of success the evolution of population dynamics in many developing countries. While population movements in the post-industrial revolution era have been influenced by sharp declines in both fertility and mortality, the net effect on population is ultimately dictated by the pattern of fertility dynamics because probabilities of mortality are bounded by an upper limit (they range between 0 and 1), while fertility can both exceed and fall short of population replacement levels. Moreover, depending on the magnitude of the technical shock affecting human capital formation both embodied and disembodied - our model shows that fertility can drop during a transitional phase of development below its long-term equilibrium level, rather than falling monotonically toward that level. This may be one possible way to explain why fertility rates have dropped below replacement levels, especially in some fast developing countries that were subject to strong technological shocks (including changes in economic policies) partly through "technology transfers" from more mature and technologically advanced economies in the second half of the $20^{\text {th }}$ century, while fertility declines in the latter have been milder and smoother over time. Also, population levels are shown to be affected more significantly by the ability of individuals to affect 
their survival odds through life and health protective behavior, as shown by the comparison between the extended model vs. the benchmark model.

Clearly, the model we have attempted to develop in this paper lends itself to additional refinements, partly by deviating more strongly from what we have interpreted as a "Malthusian framework". The purpose of this paper, nevertheless, has been to show how, by integrating the role of human capital formation within the simple Malthusian production framework, we are able to offer a model of endogenous population (fertility and mortality) and endogenous economic growth, which can explain the significant reversal of the relationship between the two over the period of persistent growth and development following Malthus's era. 


\section{REFERENCES}

Becker, G.S., "Family economics and macro behavior", American Economic Review, 78, 1988, pp. 1-13.

Becker, G.S., K.M. Murphy, and R. Tamura, "Human Capital, Fertility, and Economic Growth", Journal of Political Economy 98, 1990, pp. S12-38.

Coale, Ansley J. and Susan C. Watkins, eds., The Decline of Fertility in Europe, The Revised Proceedings of a Conference on the Princeton European Fertility Project, Princeton University Press, Princeton, 1986.

Doepke, M., Accounting for fertility decline during the transition to growth. Journal of Economic Growth 9, 347-383, 2004.

Ehrlich, Isaac and Francis T. Lui, "Intergenerational trade, longevity, and economic growth," Journal of Political Economy 99, 1029-1059, 1991.

Ehrlich, Isaac and Francis T. Lui, "The problem of population and growth: A review of the literature from Malthus to contemporary models of endogenous population and endogenous growth," Journal of Economic Dynamics and Control 21, 205-242, 1997.

Mason, Andrew, eds., Population Change and Economic Development in East Asia: Challenges Met, Opportunities Seized, Stanford University Press, Stanford, California, 2002.

Galor, O., and O. Moav, "From physical to human capital accumulation: inequality and the process of development," Review of Economic Studies, 71, 2004, 1001-26

Galor and Weil, 2000, Population, technology, and growth: from the Malthusian regime to the demographic transition and beyond, American Economic Review 90, 806-828.

Hansen, G.D., and E.C. Prescott, , Malthus to Solow, American Economic Review, 92, 2002, 1205-1217

Jones, C., "Was an industrial revolution inevitable? Economic growth over the very long-run," Advances in Macroeconomics 2, article 1, 2001.

Kalemli-Ozcan, S., "Does mortality decline promote economic growth?" Journal of Economic Growth 7, 411-439, 2002.

Kalemli-Ozcan, S., H.E. Ryder, and D.N. Weil, 2000, Mortality decline, human capital investment, and economic growth, Journal of Development Economics 62, 1-23.

Kremer, M., 1993, Population growth and technological change: one million B.C. to 1990, Quarterly Journal of Economics 108, 681-716.

Lucas, R.E., The industrial revolution: past and future, The Region, 2004, issue May, pages 5-20 
Malthus, T.R., An Essay on the Principle of Population, as it Affects the Future Improvement of Society with Remarks on the Speculations of Mr. Godwin, M. Condorcet, and Other Writers, London, Printed For J. Johnson, In St. Paul's Church-Yard, 1798.

Sato, Kazuo, "From Fast to Last: The Japanese Economy in the 1990s," Journal of Asian Economics, 13, pp. 213-35, 2002.

Tamura, Robert, "Human Capital and the Switch From Agriculture to Industry," Journal of Economic Dynamics and Control, 27, 2002: 207-242. 
Figure 1. Stable Stagnant Equilibrium

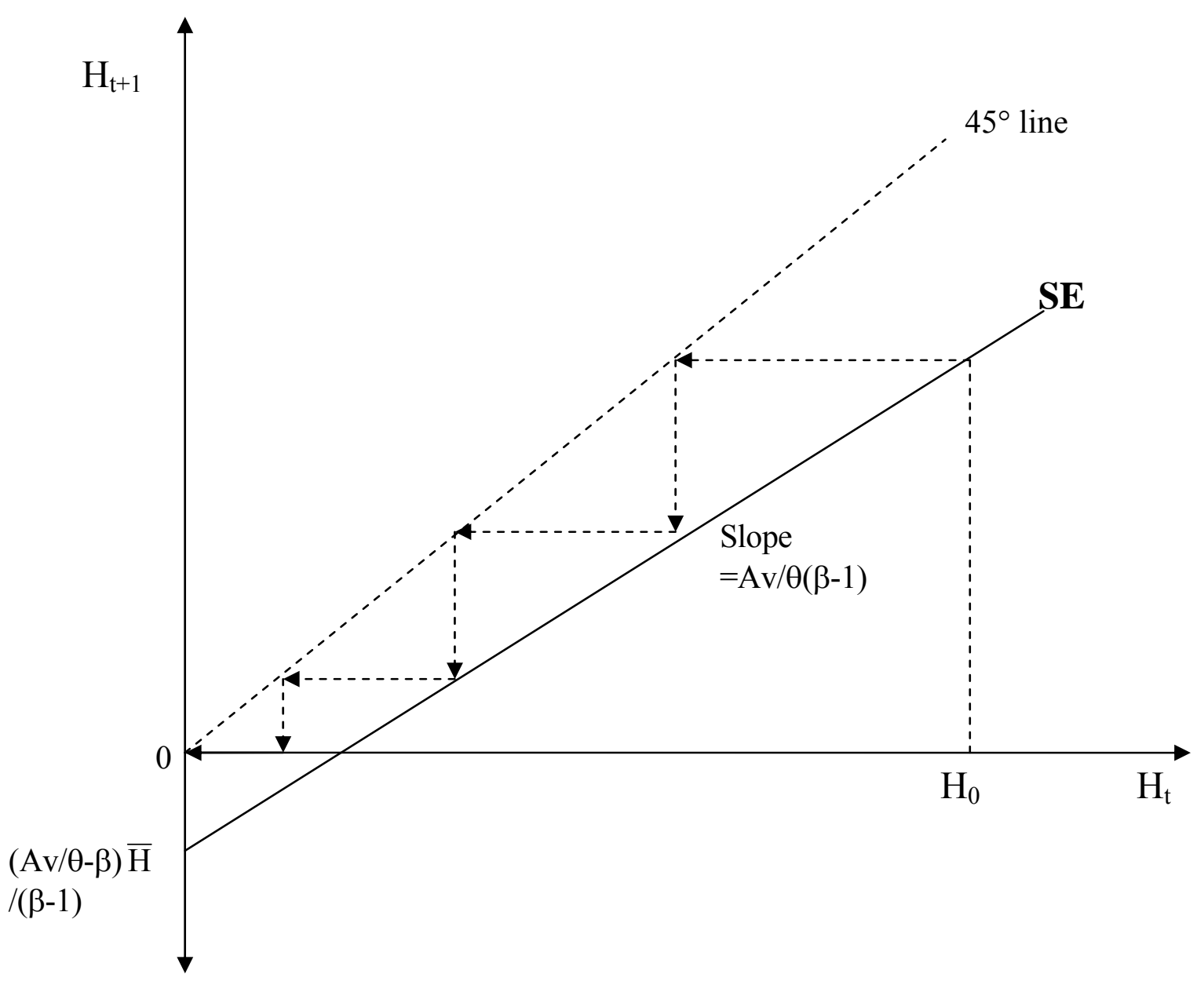


Figure 2. Transition Paths in the Benchmark Model Following a Rise in Investment Technology.

a. Human capital investment (h)

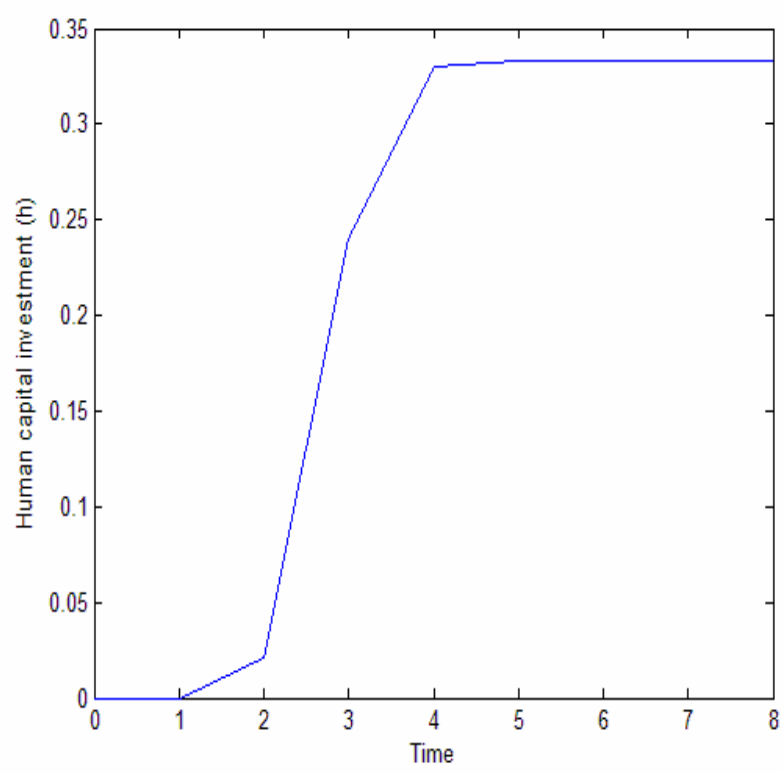

c. Survival probabilities $\left(\pi_{1}\right.$ and $\left.\pi_{2}\right)$

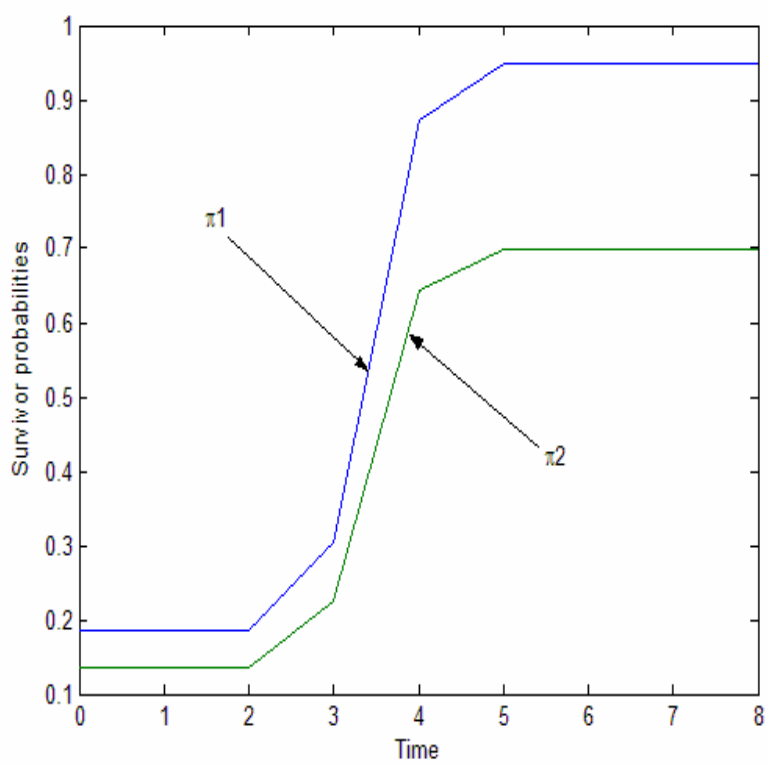

b. Level of fertility (n)

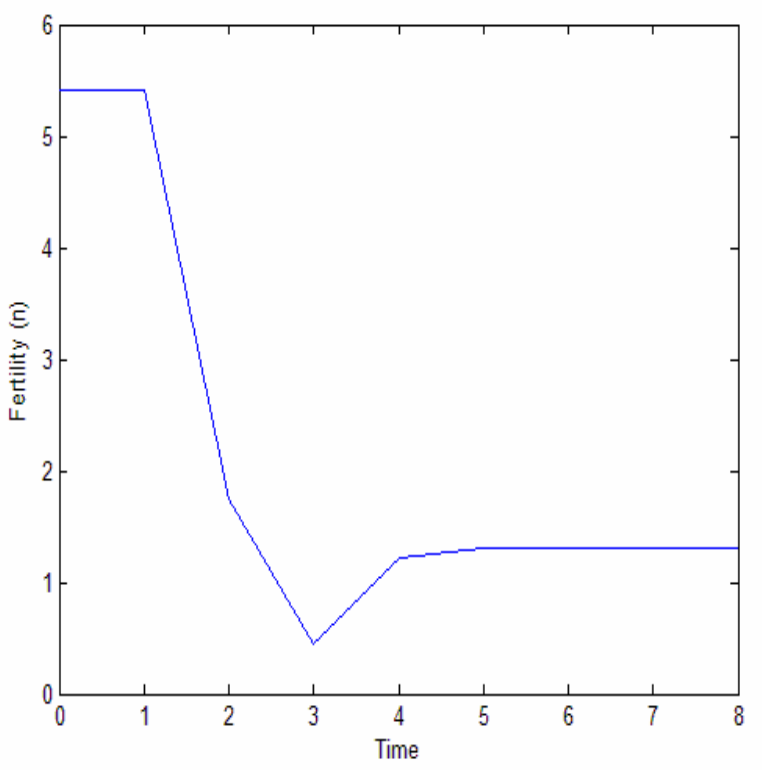

d. Population in logarithmic value

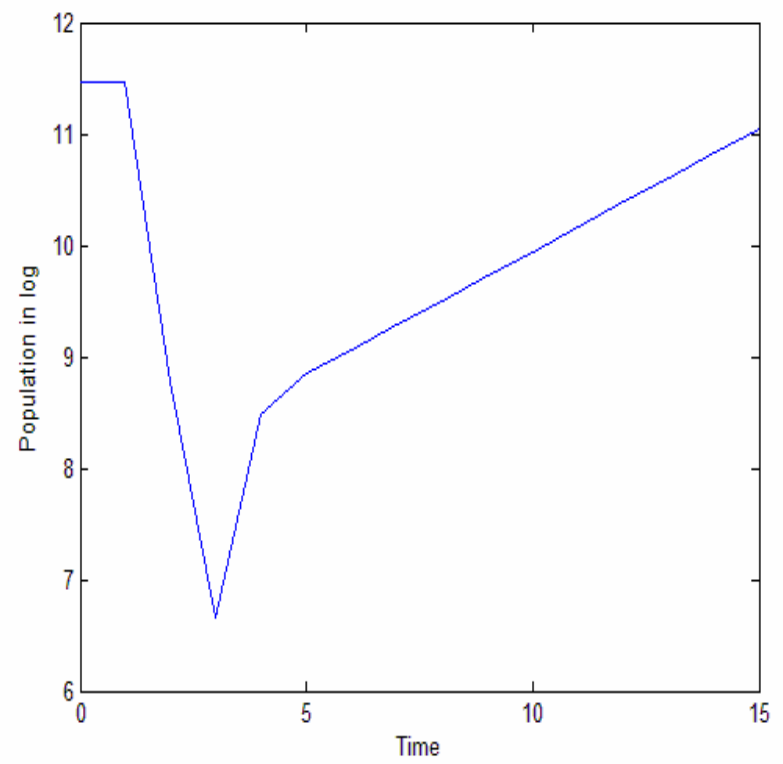


Figure 3. Transition Paths Following a Rise in both Investment Technology and Survival Probabilities

a. Human capital investment (h)

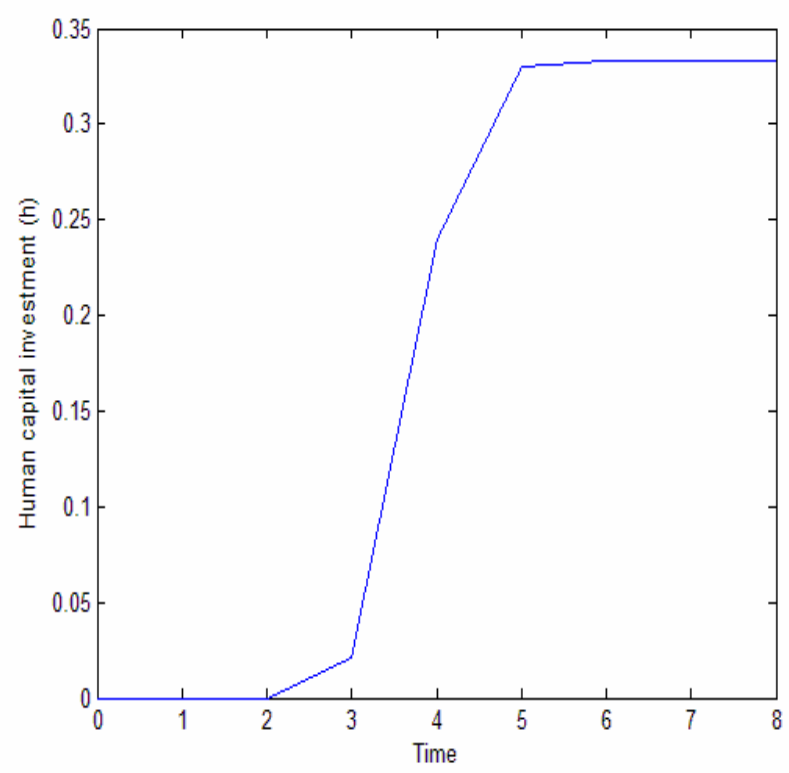

c. Survival probabilities $\left(\pi_{1}\right.$ and $\left.\pi_{2}\right)$

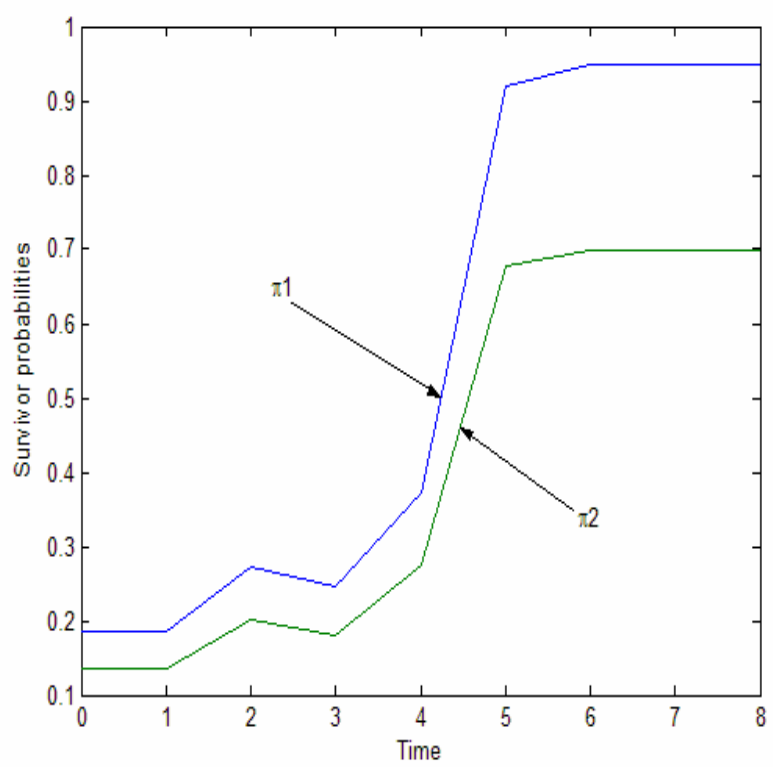

b. Level of fertility (n)

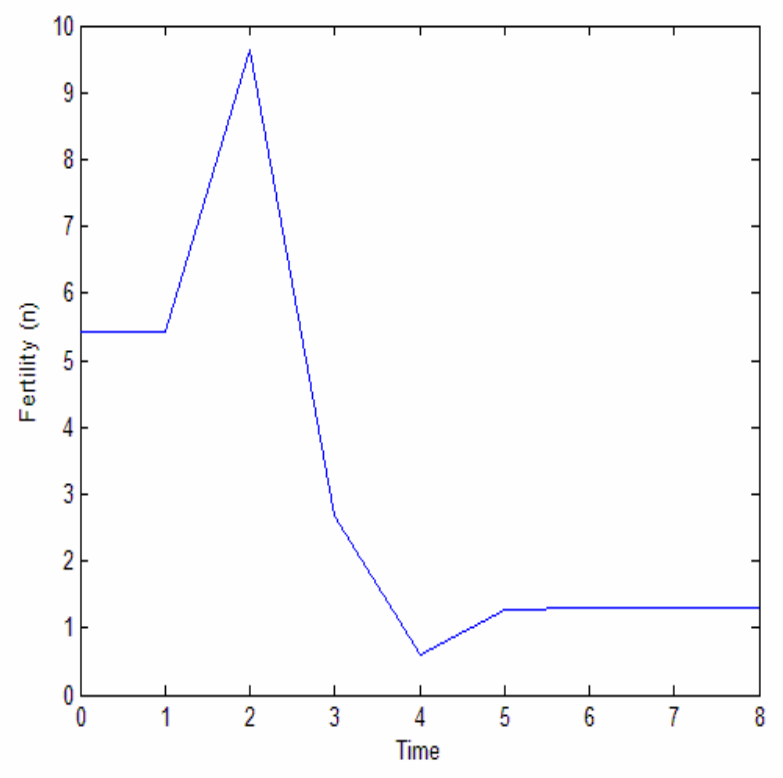

d. Population in logarithmic value

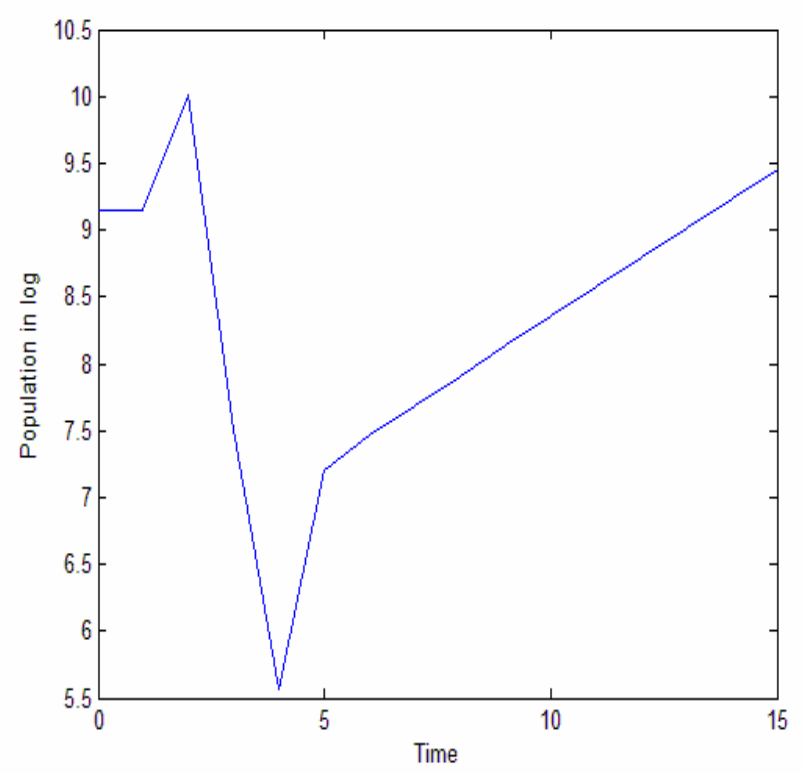


Figure 4. Transition Paths in the Extended Model Following a Rise in Investment Technology

a. Human capital investment (h)

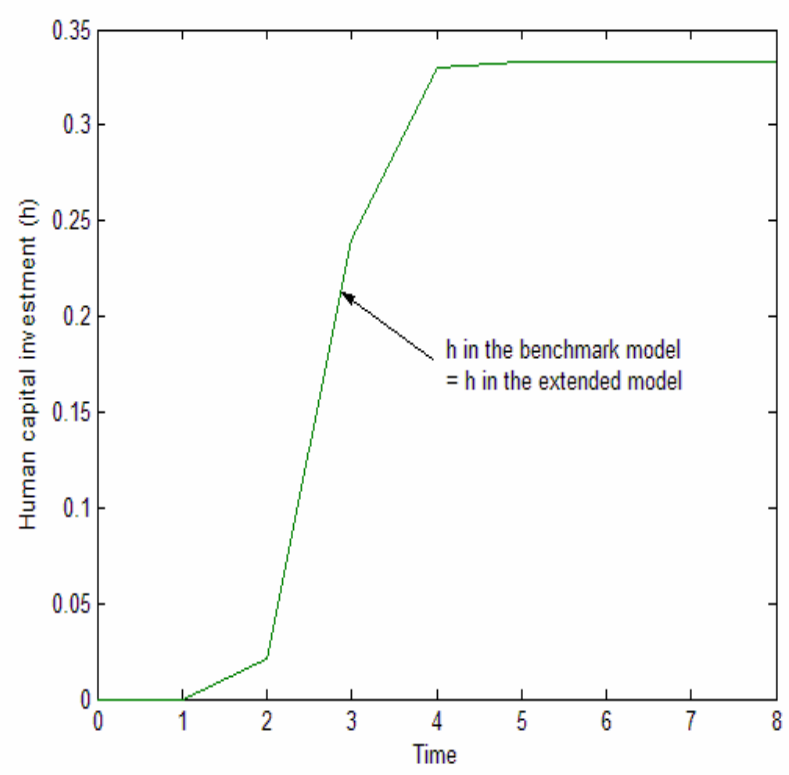

c. Survival probabilities $\left(\pi_{1}\right.$ and $\left.\pi_{2}\right)$

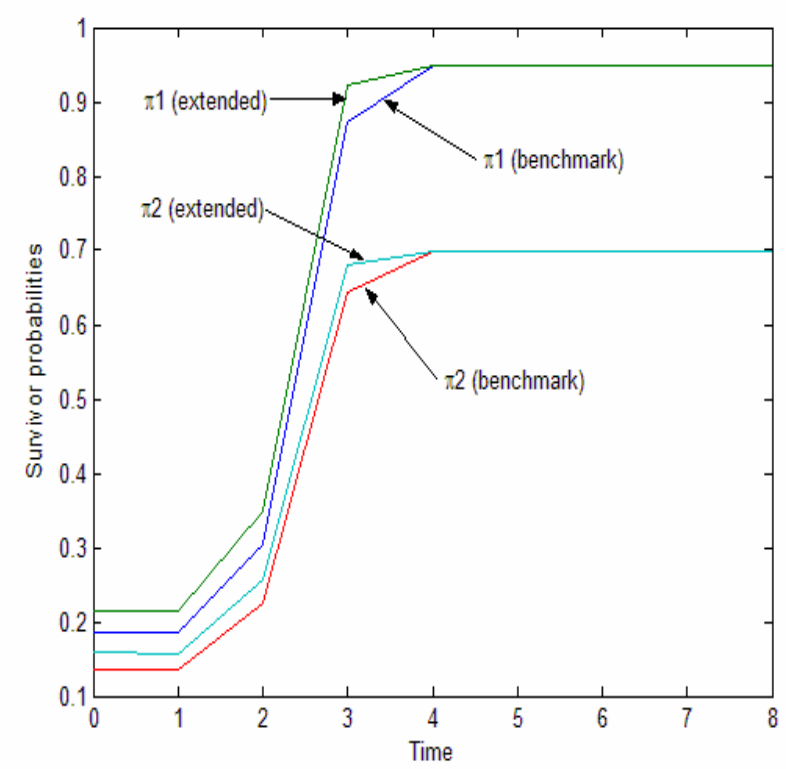

b. Level of fertility (n)

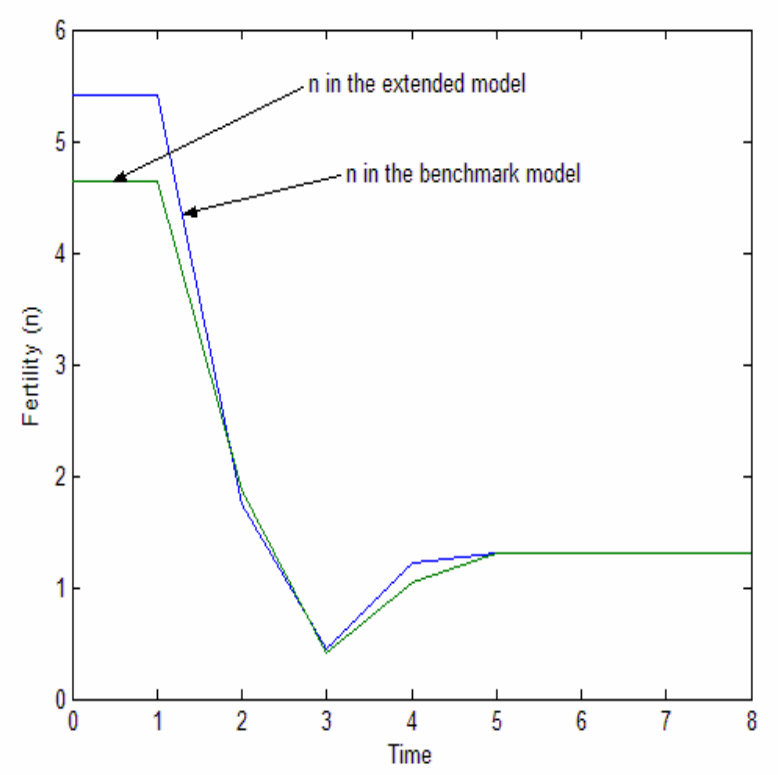

d. Population in logarithmic value

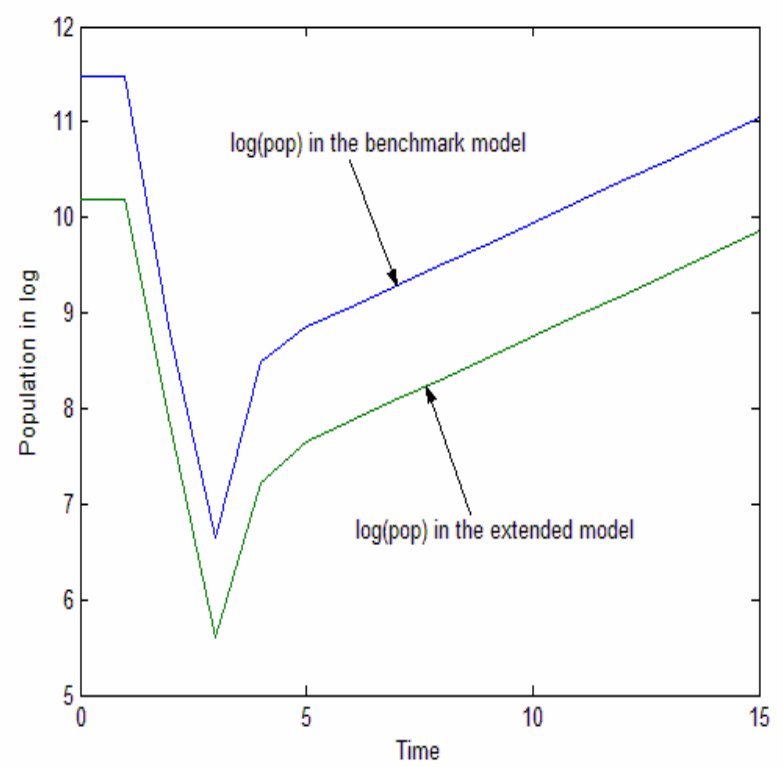

